\title{
Sustainable Alternative Composites Using Waste Vegetable Oil Based Resins
}

\author{
Felipe C. Fernandes ${ }^{1} \cdot$ Kerry Kirwan $^{1} \cdot$ Peter R. Wilson ${ }^{1} \cdot$ Stuart R. Coles $^{1}$
}

Published online: 31 July 2019

(c) The Author(s) 2019

\begin{abstract}
Laminates were produced with epoxy resins from waste vegetable oil (WVO) intended for the manufacturing of environmentally-friendly alternatives for the composites industry. Post-use cooking oil appears a promising source of triglycerides for polymer manufacturing. Matrices cured with methylhexahydrophthalic anhydride (MHHPA) were reinforced with glass and flax fibres, creating a library of composites that were compared to analogues from virgin oil and benchmarked against commercial diglycidyl ether of bisphenol A (DGEBA). Glass fibre-reinforced composites presented Young's moduli similar to the benchmark but reduced tensile strength. Chemical pre-treatment of the flax fibre $(\mathrm{NaOH}$ and stearic acid) countered the limited tensile performance observed for materials with untreated flax; improvements were evidenced by DMA and SEM. Moreover, WVO-based resins greatly improved impact properties and reduced density with no effect on thermal stability. Therefore, WVO-based composites appear as more sustainable alternatives in applications demanding toughness, stiffness and lightweight over strength.
\end{abstract}

Keywords Biocomposites $\cdot$ Natural fibres $\cdot$ Thermosetting resins $\cdot$ Mechanical testing

\section{Introduction}

Natural fibre-reinforced composites (NFRC) have gained attention in industry and academia in recent decades as an environmentally-friendly alternatives for traditional composites produced with glass fibres (GFRC) [1]. Vegetable fibres have been rediscovered as reinforcing agents and extensively investigated in applications with thermoplastic and thermoset matrices [2]. They present advantages over traditional fibres such as reduced density, price, renewability, biodegradability, and lower environmental burdens [3]. Consequently, NFRC have demonstrated their successful applicability in a number of segments, ranging from automotive sector (both in interior and exterior applications), construction, design and packaging industry [4-8].

Nevertheless, the utilisation of petroleum-derived resins for the production of composite laminates reduces the overall environmental benefits of using NFRC [9]. The use of these resins not only restricts the potential reductions

Stuart R. Coles

Stuart.Coles@warwick.ac.uk

1 WMG, University of Warwick, Gibbet Hill Road, Coventry CV4 7AL, UK in carbon footprint, but also presents challenges regarding eco- and human toxicity [10]. For example, diglycidyl ether of bisphenol A (DGEBA), a molecule predominantly used in the epoxy resin market, uses bisphenol A (BPA) as a precursor [11]. This molecule is a recognised teratogenic agent, endocrine disruptor, presents long lasting effects to aquatic life, and has been removed from polymers used in baby bottles [12-14]. Specifically, bisphenol-based networks such as those formed with DGEBA can release BPA even after curing since these cross-linked units are susceptible to hydrolysis [11].

Increasing environmental concerns, tighter legislation and awareness about the toxicity of these resins have driven stakeholders to seek more sustainable alternatives for the thermoset composite market $[15,16]$. In this regard, the community has explored the production of thermoset matrices from environmentally-friendly resins as a strategy to reduce the manufacturing impacts [17-19]. Amongst different candidates, vegetable oils (VOs) have been considered as a key platform to enable a shift towards a greener polymer industry due features such as price, availability, safety and chemical versatility [20]. The main chemical constituent of VOs, triglycerides, can be manipulated with ease to produce resins with different functionalities such as epoxy, maleic and acrylated resins, therefore 
enabling a wide range of applications [21-24]. Consequently, VO-based resins have successfully demonstrated in the preparation of biocomposites reinforced with vegetable fibres such as hemp [25, 26], flax [27, 28], kenaf, switchgrass [29], wheat straw and recycled paper [27]. These approaches manufactured composites combining competitive mechanical properties with increased bio-based content. Most importantly, these materials proved to be able to deliver extra properties such as biodegradability and improved impact performance in comparison to traditional resins [30, 31].

The production of polymeric networks from waste vegetable oil (WVO) offers opportunity for the production of a next generation of bio-based materials based on the waste valorisation principle [32]. The exploration of this post-use material (which can be collected from food outlets, households etc.) is aligned with sustainable principles [33-35]. Since WVO becomes a non-edible feedstock after the frying process, its use alleviates potential pressures on the commodity food price caused by the exploration of vegetable oils in engineering applications [36, 37]. Additionally, its valorisation combats hazardous practices of human and animal consumption of reprocessed oil [38]. Finally, the use of WVO as a technological feedstock also diminishes environmental impacts associated with the production phase of the resin as WVO can be assumed as a burden-free feedstock [39].

The incorporation of WVO-derived triglycerides into epoxy-based polymer networks has been recently demonstrated in the literature [33]. Partially bio-based matrices enabled the production of composites with recycled carbon fibres by resin casting with maximum of Young's Modulus of $3.2 \mathrm{GPa}$ and a tensile strength of $53 \mathrm{MPa}$. This investigation permitted further development of networks entirely derived from epoxy resins synthesised from WVO [40]. In the current study, we report the first production of a library of composites exploring the combination between WVObased matrices with fibres such as glass and flax. These matrices are compared to analogues produced from neat vegetable oil to investigate effects of the use-phase in the resulting networks. The study also investigates the use of different molar ratios of curing agent in the system, aiming to find the best balance between final properties of the thermoset and renewable content. Chemical modification steps were implemented to NFRC in order to improve fibre/matrix adhesion and produce more competitive materials from a mechanical performance standpoint.

\section{Materials and Methods}

\section{Materials}

Waste vegetable oil (used for deep frying for 4 days, a blend of rapeseed/palm oil approximately $3: 1$ ) and pre-use vegetable oil (same blend) were collected from a food outlet at the University of Warwick, Coventry, UK. Hydrogen peroxide $(30 \% \mathrm{v} / \mathrm{v})$, toluene (puriss. p.a. $>99.7 \%)$, dichloromethane (puriss. 99\%), methyl-hexahydrophtalic anhydride (MHHPA, 96\%, mixture of isomers cis and trans) and 2-methylimidazole (2-MI, 99\%) were supplied by Sigma-Aldrich UK. Stearic acid, ethanol, $\mathrm{MgSO}_{4}$ (dried), $\mathrm{NaHCO}_{3}$ and $\mathrm{NaOH}$ were supplied by VWR International. All chemicals, with the exception of the WVO, were used as received. Flax fibres (Biotex Flax Fiber 2/2 Twill 200 GSM) and Glass fibres (Woven Glass 2/2 Twill 280 GSM) were supplied by Easy Composites Ltd, UK. Bio-based epoxy resins were synthesised from purified waste vegetable oil (epoxidized purified vegetable oil-EPVO) and neat vegetable oil (epoxidized neat vegetable oil-ENVO) according to previous reported methodologies [33]. Super Sap CLR ${ }^{\circledR}$ Part A was used as the epoxy part A (DGEBA, Entropy Resins, United States) and a part B of hardener (mixture of isophorone diamine and 1,3-benzenedimethanamine, Entropy Resins, United States) as the benchmark epoxy.

\section{Flax Fibre Modification}

For the mercerization treatment, flax fibres $\left(40 \times 40 \mathrm{~cm}^{2}\right.$ plies) were immersed in aqueous $\mathrm{NaOH}$ solution (4 wt $\%$ ) at room temperature and remained under stirring for $1 \mathrm{~h}$. The $4 \mathrm{wt} \%$ concentration was chosen as it has previously been shown to produce fibres with the highest tensile strength [41]. After this time, fibres were carefully washed with distilled water to remove excess $\mathrm{NaOH}$ and oven dried (ThermoScientific Heraterm, $95{ }^{\circ} \mathrm{C}$ for $6 \mathrm{~h}$ ). Fibres obtained from this methodology were denominated NFF. For the treatment with stearic acid, flax fibres $\left(40 \times 40 \mathrm{~cm}^{2}\right.$ plies $)$ were submerged in a $3 \mathrm{wt} \%$ stearic acid solution in ethanol and continuously stirred at $70{ }^{\circ} \mathrm{C}$ for $1 \mathrm{~h} .3 \mathrm{wt} \%$ treatment with stearic acid has previously been used to improve the mechanical properties of natural fibres [42]. After the treatment, fibres were oven dried (ThermoScientific Heraterm, $95{ }^{\circ} \mathrm{C}$ for $6 \mathrm{~h}$ ). Fibres obtained through this methodology are denominated SFF.

\section{Composite Manufacturing}

Reinforcing fibres were cut into $40 \times 40 \mathrm{~cm}^{2}$ squares from the roll of material, and oven dried (ThermoScientific Heraterm) at $95{ }^{\circ} \mathrm{C}$ for $4 \mathrm{~h}$ prior to the lamination. In order to obtain panels of suitable thicknesses for the mechanical tests $(2 \mathrm{~mm})$, two plies of flax fibres and four plies of glass fibres were used in the lamination process. After drying, fibres were weighed to allow the calculation of the resin content required to produce formulations with constant volume fraction (30 vol\%) of the reinforcing agent. This strategy was adopted to manufacture panels presenting similar 
level of reinforcement agents despite the inherent differences between glass and flax fibres in terms of density. Conversions between vol\% and $\mathrm{wt} \%$ were performed considering the following densities: $\rho_{\text {Flax }}=1.5 \mathrm{~g} \mathrm{~cm}^{-3}, \rho_{\text {Glass }}=2.5 \mathrm{~g} \mathrm{~cm}^{-3}$ and $\rho_{\text {Matrix }}=1.07 \mathrm{~g} \mathrm{~cm}^{-3}$ [3]. The thermoset resin was formulated through the addition of an appropriate amount of bio-derived epoxy resin (EPVO or ENVO) into a $250 \mathrm{~mL}$ round bottom flask. The catalyst (2-MI) was added to the system and the mixture was heated at $100{ }^{\circ} \mathrm{C}$ under constant stirring to allow the solubilisation of the catalyst into the system. The mixture was kept under these conditions for $5 \mathrm{~min}$, and thereafter an appropriate amount of hardener (MHHPA) was added to the system according to proportions presented in Table 1, producing anhydride-rich (1.4:1.0) and oil-rich $(1.0: 1.0)$ systems. Formulations were thoroughly homogenized for $3 \mathrm{~min}$ to ensure proper mixing between components.

Laminates were produced by combination of intercalating layers of resin and reinforcing fibres by wet lay-up. The resin was applied using a bush and a paddle roller to ensure plies were being well wetted. Panels were laminated against a steel plate covered with PTFE and cured (ThermoScientific Heraterm) according to the following heating/cooling regime: $50{ }^{\circ} \mathrm{C}$ to $140{ }^{\circ} \mathrm{C}$ at $1.5{ }^{\circ} \mathrm{C} \mathrm{min}^{-1} ; 10 \mathrm{~h}$ at $140{ }^{\circ} \mathrm{C}$; and $140{ }^{\circ} \mathrm{C}$ to $50{ }^{\circ} \mathrm{C}$ at $-1.5{ }^{\circ} \mathrm{C} \mathrm{min}^{-1}$. Resulting panels were post-cured according to the following regime: from 50 to $160{ }^{\circ} \mathrm{C}$ at $1.5^{\circ} \mathrm{C} \mathrm{min}^{-1}, 2 \mathrm{~h}$ at $160{ }^{\circ} \mathrm{C}$; and $160{ }^{\circ} \mathrm{C}$ to $50{ }^{\circ} \mathrm{C}$ at $-1.5^{\circ} \mathrm{C} \min ^{-1}$. Equivalent panels were produced with DGEBA (SuperSap CLR ${ }^{\circledR}$ ) to benchmark the biocomposites against a known commercial formulation, and the cure regime was adjusted according to the recommendations of the resin manufacturer. Table 1 presents a breakdown of the components utilised in each formulation. Composites prepared with the chemically modified fibres in later stages followed the manufacturing procedure and adopted the same

Table 1 Summary of the composite formulations prepared in the study according to the origin of the epoxy resin, molar ratio of curing agent and reinforcing fibre

\begin{tabular}{llll}
\hline Formulation & $\begin{array}{l}\text { Molar ratio } \\
\text { (anhydride:epoxy) }\end{array}$ & $\begin{array}{l}\text { Epoxy resin } \\
\text { origin }\end{array}$ & Reinforcing fibre \\
\hline 10 Neat FF & $1.0: 1.0$ & Neat oil & Virgin flax (FF) \\
14 Neat FF & $1.4: 1.0$ & Neat oil & Virgin flax (FF) \\
10 Purif FF & $1.0: 1.0$ & Purified WVO & Virgin flax (FF) \\
14 Purif FF & $1.4: 1.0$ & Purified WVO & Virgin flax (FF) \\
DGEBA FF & $*$ & DGEBA & Virgin flax (FF) \\
10 Neat GF & $1.0: 1.0$ & Neat oil & Glass (GF) \\
14 Neat GF & $1.4: 1.0$ & Neat oil & Glass (GF) \\
10 Purif GF & $1.0: 1.0$ & Purified WVO & Glass (GF) \\
14 Purif GF & $1.4: 1.0$ & Purified WVO & Glass (GF) \\
DGEBA GF & $*$ & DGEBA & Glass (GF) \\
\hline
\end{tabular}

nomenclature, with NFF and SFF suffix indicating the fibre used.

\section{Characterisation of the Materials}

Characterization of the bio-based epoxy resins (EPVO and ENVO) was performed by Infrared spectra (ATR-FTIR) and ${ }^{1} \mathrm{H}$ Nuclear Magnetic Resonance $\left({ }^{1} \mathrm{H}\right.$ NMR) according to the methodologies previously described in literature [33]. Weight-loss curves were obtained by thermogravimetric analysis (TGA) using a Mettler Toledo TGA 1 STARe programmed to heat the sample from 25 to $600^{\circ} \mathrm{C}$, with heating rate of $10{ }^{\circ} \mathrm{C} \mathrm{min}^{-1}$, under $\mathrm{N}_{2}$ flow of $100 \mathrm{~mL} \mathrm{~min}{ }^{-1}$. The initial temperature of degradation $\left(\mathrm{T}_{\text {Onset }}\right)$ was defined from the main thermal event and the temperature of maximum degradation rate $\left(\mathrm{T}_{\mathrm{Max}}\right)$ was determined from the maximum of the 1st derivative curve of percentage of weight loss with respect to temperature. Dynamic Mechanical Analysis (DMA) was conducted using a dual cantilever configuration, with oscillating frequency of $1.0 \mathrm{~Hz}$, displacement of $0.05 \mathrm{~mm}$, temperature range of -100 to $120^{\circ} \mathrm{C}$, heating rate of $2{ }^{\circ} \mathrm{C} \mathrm{min}{ }^{-1}$. Samples were cut in rectangular format with nominal dimensions of $1.5 \times 5 \times 24 \mathrm{~mm}$. The glass transition temperature $\left(\mathrm{T}_{\mathrm{g}}\right)$ was defined from the maximum of the peak of $\tan \delta$ in curves of $\tan \delta$ versus temperature.

For the tensile tests, composite panels were dimensioned according to ASTM D3039/D3039M. Tests were performed using a universal test machine (Instron $30 \mathrm{kN}$ Static Load Cell) with extensometer $(80 \mathrm{~mm})$, at test speed of $2 \mathrm{~mm} \mathrm{~min}{ }^{-1}$. A minimum of seven specimen were successfully tested for each formulation. Charpy impact tests were performed according to ASTM D4812-1, with a pendulum adjusted for a $7.5 \mathrm{~J}$ impact force (Ray Ran Pendulum Impact Tester) and a flatwise impact. A minimum of seven speciment of nominal size $3 \times 25 \times 100 \mathrm{~mm}$ (unnotched) were successfully tested for each formulation. To obtain Scanning Electron Microscopy images (SEM, Hitachi TM3030Plus), untested impact test samples were cryo-fractured after immersion in liquid $\mathrm{N}_{2}$ for $10 \mathrm{~min}$, and dimensioned according to the sample holder size. Prior to the analysis, the surface of the samples was metallized for best results. Images were obtained using secondary electron (SE) beam with acceleration voltage of $15 \mathrm{kV}$.

\section{Results and Discussion}

\section{Characterisation of Formulation Components}

Bio-based epoxy resins used in this study were synthesised according to procedures previously developed in our group, Fig. 1 [33]. Although WVO presents a number of impurities and by-products deriving from hydrolysis and thermal 
oxidation during the frying process, the development of purification methodologies based on liquid-liquid (L-L) extraction was capable of producing a clean source of triglycerides [43].

These molecules were then epoxidized using a peracid approach, capable of producing EPVO with up to 2.11 oxirane rings per triglyceride unit. It is important to emphasise that control over the degree of functionality could be established according to the relationship between the number of unsaturation sites in the vegetable oil (determined by ${ }^{1} \mathrm{H}$ NMR) and the epoxidation stoichiometry. Resins produced from virgin oil followed the same procedure, only with adjustments in the quantities of the reagents to reflect the different degree of unsaturation; ENVO contained 2.66 oxirane rings per unit.

Compatibilization between the hydrophilic nature of vegetable fibres and the hydrophobicity of the polymeric matrix is a well-known challenge with NFRC [5]. Therefore, composites reinforced with flax were prepared with the fibre in natura and also after mercerization and stearic acid-based treatments, methodologies which have been recurrently explored in literature. Mercerization chemically removes lignin, hemicellulose and waxes from the surface of the fibres, consequently increasing the relative content of cellulose and the nature of the surface charges [44]. A secondary effect of this treatment is the fibrillar rearrangement caused by ionization of hydroxyl groups, leading to fibrillation and consequently higher surface area and aspect ratio. This feature improves mechanical interlocking between fibre and matrix. Conversely, stearic acid-based treatment functionalizes the surface by esterification, simultaneously reducing the concentration of hydroxyls on the surface whilst attaching long aliphatic chains $\left(\mathrm{C}_{17}\right)$ to the fibre. reducing its polarity [45].

ATR-FTIR spectra of fibre samples after the chemical treatment (Fig. 2) revealed a decrease in signals at $1730 \mathrm{~cm}^{-1}$ and $1450 \mathrm{~cm}^{-1}$, evidencing partial removal of hemicellulose and lignin, respectively [46]. Interestingly, the region between 3300 and $3500 \mathrm{~cm}^{-1}$, associated with the $\nu \mathrm{O}-\mathrm{H}$ of cellulose molecules does not show any significant changes with respect to its shape. This observation indicates that despite the decrease in the levels of hemicellulose and lignin there are no significant transformations in the inter- and intramolecular arrangement between the cellulose chains [47]. Also, the signal present at $1703 \mathrm{~cm}^{-1}$ exclusively observed in the SFF sample is associated with $v$ $\mathrm{C}=\mathrm{O}$ in stearic acid.

Changes in the fibre surface and morphology were also monitored through electron microscopy images. Topological and microstructural arrangement of the flax fibres were dramatically altered by both treatments (Fig. 3). Surfaces became more irregular, with increased roughness and presence of grooves that can act as point of physical interaction with the matrix [48]. Medium and high magnification images revealed the effect of fibrillation, which is characterized by the opening of the fibre bundles. The surface of SFF fibres also indicate the presence of points of accumulation of stearic acid and that the fibres are physically covered by a thin layer of the fatty acid. For comparison, micrographs of glass fibres are also included.

Thermogravimetric curves of the reinforcing fibres demonstrated that NFF fibres were less thermally stable than the untreated flax fibres $\left(\mathrm{T}_{\text {Onset }}\right.$ of 297.2 and $323.2^{\circ} \mathrm{C}$, respectively). As NFF fibres becomes proportionately richer in cellulose, the other components lose the ability to protect the polysaccharide chains from thermal degradation [49]. It should be noted, however, that other studies also have

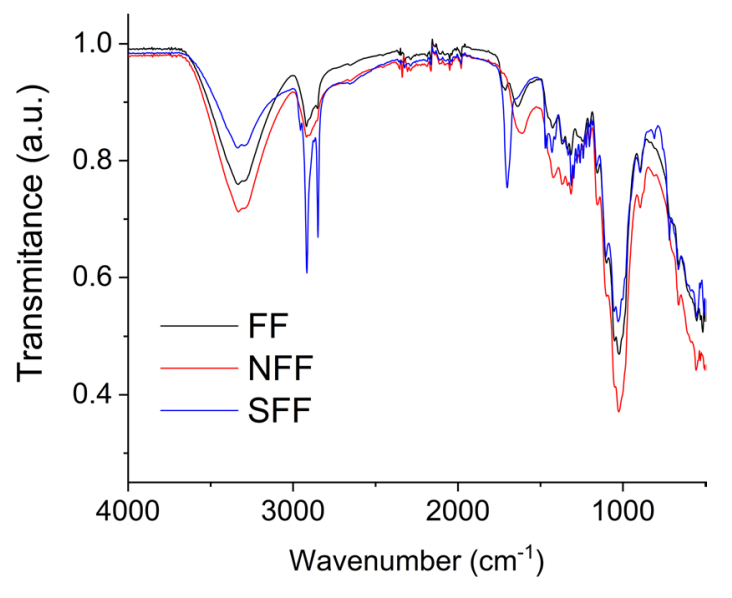

Fig. 2 ATR-FTIR spectra of the flax fibre before (FF) and after the alkaline (NFF) and stearic acid (SFF) treatments, from 4000 to $500 \mathrm{~cm}^{-1}$

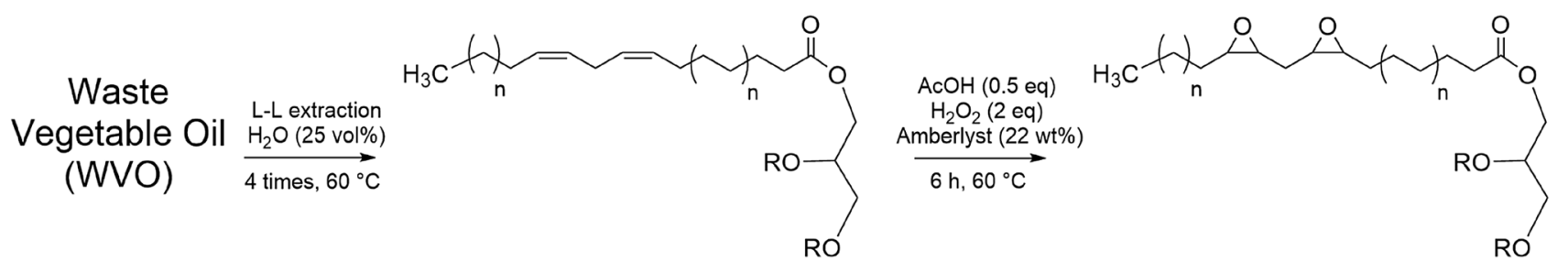

Fig. 1 Representation of the production of epoxy resins from waste vegetable oil 

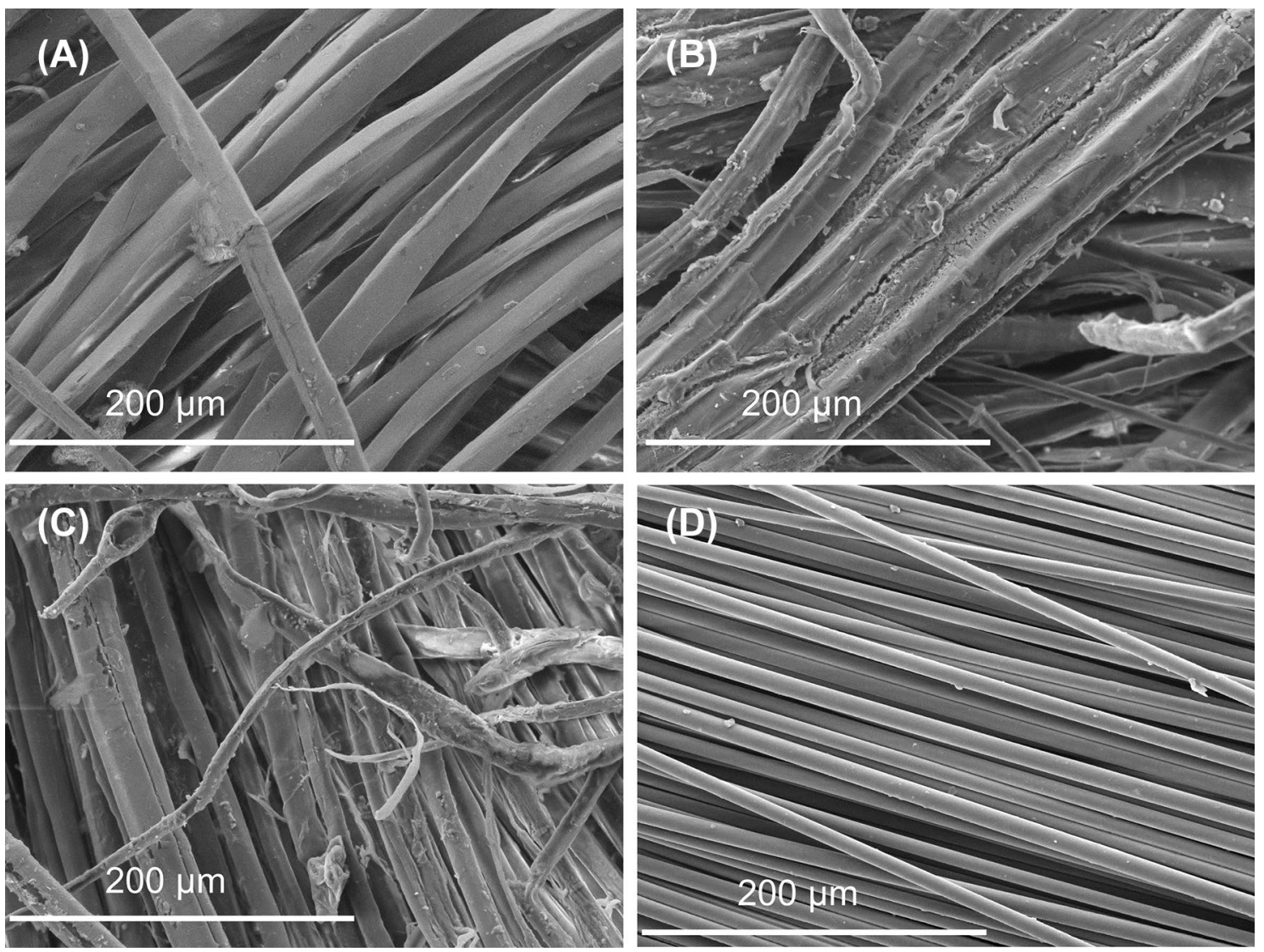

Fig. 3 SEM images of a untreated flax fibres (FF), b NaOH-treated fibres (NFF), c stearic acid-treated fibres (SFF) and d glass fibres (GF), magnification of $\times 500$

illustrated that the thermal stability of some fibres can be also increased by the alkaline treatment process due to removal of less stable fractions [50]. This demonstrates the importance of finding a balance between time and concentration of the alkali solution in this kind of treatment. On the other hand, SFF presents increased thermal stability $\left(\mathrm{T}_{\text {Onset }}\right.$ of $336.1{ }^{\circ} \mathrm{C}$ ), which is attributed to the addition of stearic acid to the structure. Fatty acid segments create a barrier effect that prevents the thermal degradation of the cellulose units [51]. Values of $\mathrm{T}_{\text {Max }}$ follow the same behaviour observed for $\mathrm{T}_{\text {Onset }}$ (Table 2). Thermogravimetric curve of glass fibres demonstrate the superior thermal stability of this material since no degradation was observed in this temperature range.

\section{Mechanical Performance of Glass Fibre Reinforced Composites}

The first group of laminates manufactured for creation of the WVO-based composites library were reinforced with glass fibres due to the commercial significance of this reinforcing agent in the composite market. Table 3 presents values of Young's modulus and tensile strength for composites
Table 2 Initial temperature of degradation $\left(\mathrm{T}_{\text {Onset }}\right)$ and maximum degradation $\left(\mathrm{T}_{\mathrm{Max}}\right)$ temperatures of the treated flax fibres (NFF and $\mathrm{SFF}$ ) compared to virgin fibre (FF) and glass fibres (GF)

\begin{tabular}{lll}
\hline Formulation & $\mathrm{T}_{\text {Onset }}\left({ }^{\circ} \mathrm{C}\right)$ & $\mathrm{T}_{\text {Max }}\left({ }^{\circ} \mathrm{C}\right)$ \\
\hline GF & Do not degrade & Do not degrade \\
FF & 323.2 & 357.7 \\
NFF & 297.2 & 339.3 \\
SFF & 336.1 & 372.1 \\
\hline
\end{tabular}

reinforced with glass fibres. GFRC materials prepared with WVO-based epoxy and anhydride-rich matrix (14 Purif GF) exhibited tensile modulus ( $7.6 \pm 2.1 \mathrm{GPa})$, which is statistically equivalent to those observed for the reference formulation produced virgin oil $(7.8 \pm 1.1 \mathrm{GPa})$ and the commercial benchmark with DGEBA $(8.3 \pm 0.3 \mathrm{GPa})$. These results demonstrate the capacity of production of alternative materials with highly elastic character that emulates the benchmark material even though it comes from waste sources. The comparison of these materials with those produced with oil-rich networks ( 10 Neat GF and 10 Purif GF) demonstrate the reduction in tensile moduli of $22 \%$ and $17 \%$ lower, 
Table 3 Tensile properties, density and impact strength of composites reinforced with GF

\begin{tabular}{lllllc}
\hline Formulation & $\begin{array}{l}\text { Young's modu- } \\
\text { lus (GPa) }\end{array}$ & $\begin{array}{l}\text { Tensile } \\
\text { strength (MPa) }\end{array}$ & $\begin{array}{l}\text { Elongation at } \\
\text { break (\%) }\end{array}$ & Density $\left(\mathrm{g} \mathrm{cm}^{-3}\right)$ & $\begin{array}{l}\text { Impact } \\
\text { strength }(\mathrm{kJ} \\
\left.\mathrm{m}^{-2}\right)\end{array}$ \\
\hline 10 Neat GF & $6.3 \pm 0.4$ & $77 \pm 10$ & $4.3 \pm 1.2$ & $1.37 \pm 0.03$ & $76 \pm 8$ \\
14 Neat GF & $7.6 \pm 2.0$ & $91 \pm 22$ & $1.3 \pm 0.4$ & $1.41 \pm 0.02$ & $87 \pm 12$ \\
10 Purif GF & $6.0 \pm 0.2$ & $26 \pm 5$ & $6.6 \pm 3.1$ & $1.33 \pm 0.04$ & $141 \pm 14$ \\
14 Purif GF & $7.7 \pm 1.1$ & $46 \pm 5$ & $7.2 \pm 1.0$ & $1.37 \pm 0.04$ & $117 \pm 23$ \\
DGEBA GF & $8.3 \pm 0.4$ & $151 \pm 14$ & $2.1 \pm 0.1$ & $1.51 \pm 0.02$ & $51 \pm 8$ \\
\hline
\end{tabular}

respectively. The incorporation of less hardener molecules in the network can be associated with an overall reduced rigidity and less tightly connected cross-linked networks.

Similar effects are observed in terms of tensile strength, which proved to be dependent on the oil origin and the amount of hardener in the formulation. In this regard, the superior strength of laminates produced with ENVO can be associated with the higher number of oxirane rings per unit of triglyceride due to its unsaturated nature [40]. In terms of molar ratio, the use of an excess of MHHPA lead to an increase of $77 \%$ in the tensile strength of materials produced with WVO. Therefore, adjustments in the formulation from the hardener point of view prove to be a key factor to control the properties of the resulting composites and mitigate the reductions caused by the less functionalised resin (EPVO).

Although these vegetable oil-derived networks demonstrated Young's moduli property comparable with the commercial benchmark, no bio-based formulation rival the DGEBA composites in terms of tensile strength $(150 \pm 13 \mathrm{MPa})$ due to differences in the molecular backbone. In fact, the use of triglyceride-based epoxies instead of DGEBA reduces the aromatic character of the network, which is responsible for providing high strength properties due to good intermolecular forces. Nevertheless, these results demonstrate that GFRC produced from WVO are valid alternatives where stiffness is more critical than tensile strength.

Most importantly, the use of WVO-based resin led to improvements in comparison with other systems in some areas. For example, the substitution of DGEBA for WVO resulted in a reduction of $12 \%$ in density, therefore being an attractive alternative for applications where weight reduction is a critical design parameter. Moreover, significant improvements were observed in impact resistance due to the utilization of bio-based epoxy. Composites manufactured with WVO-based resins demonstrate higher impact strength than laminates produced with neat oil and DGEBA (up to $86 \%$ and $176 \%$, respectively). This feature is a consequence of the capacity of quick relaxation of networks based on long aliphatic chains, therefore facilitating the phenomenon of the rapid energy dissipation through chain relaxation [52]. These results represent substantial improvements since DGEBA is known for its brittle nature with poor resistance to crack propagation [53]. The reduction in brittleness through the use of bio-based is also observed in higher values of elongation at break. Additional control of over the impact performance was achieved by the use of different amounts of hardener: anhydride-rich networks presented lower impact strength associated with the creation of denser and more rigid networks with reduced capacity for fast relaxation.

Figure 4 summarises the findings for GFRC in a radar plot format, comparing mechanical and physical properties of the best composite prepared with WVO versus the laminates manufactured with virgin vegetable oil and DGEBA matrices. The plot visually demonstrated that materials herein produced can compete with other resins in uses that demand increased toughness, stiffness and lighter weight over strength. In addition, the renewable character of the formulation was improved without sacrifices in Young's modulus. Finally, a trade-off between impact strength and tensile strength can be identified as a critical design parameter when selecting WVO or virgin vegetable oil as feedstock to produce the bio-based resins.

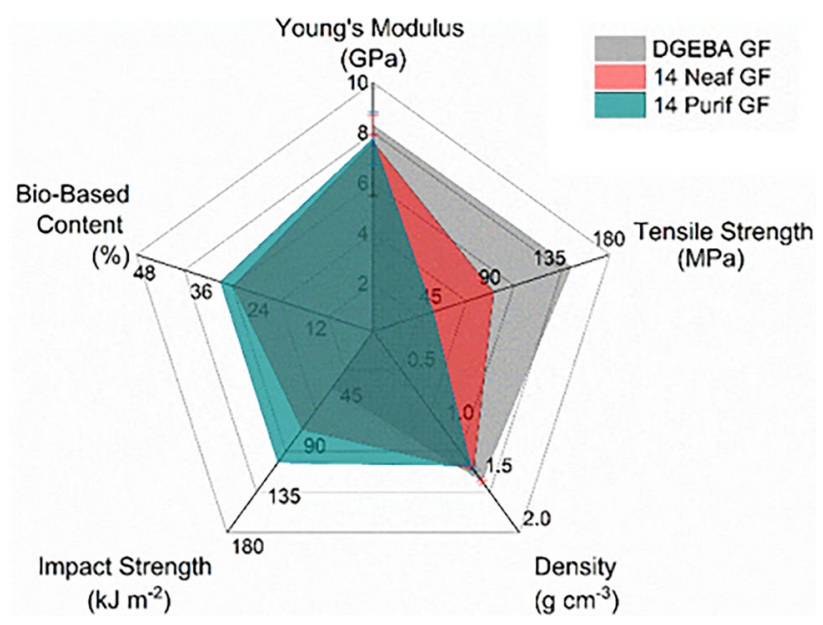

Fig. 4 Radar plot of composites reinforced with glass fibres produced with waste oil and neat oil-based resins versus DEGBA reference in terms of mechancial properties (tensile and impact), density and biobased content 


\section{Mechanical Performance of Flax Fibre Reinforced Composites}

The library of composite laminates from WVO was expanded through the produced based on NFRC as an approach to manufacture materials with improved the environmental performance and distinct properties from GF equivalents. In this regard, materials combining EPVO and untreated natural fibres presented a maximum Young's Modulus $0.60 \pm 0.05 \mathrm{GPa}$ and tensile strength of $22.7 \pm 0.9 \mathrm{MPa}$ of tensile strength, Table 4 . The utilisation of resins produced from neat oil produced laminates with very similar properties, while $D G E B A-F F$ resulted in laminates with much superior performance. These differences illustrate the challenge of compatibilizing the triglyceride-based matrices and the untreated natural fibres, which present a highly hydrophilic nature, and therefore producing components for structural applications.

Similarly to what observed for GFRC, values of tensile strength and tensile modulus fluctuated according to the relationship with anhydride content and the resin origin. Therefore, networks more tightly connected and presenting a higher ratio of the most rigid moiety presented better tensile performance. Despite the modest specific tensile moduli, it is noteworthy that reductions of up to $27 \%$ were obtained in the density values by the replacement of glass by untreated flax fibres. This represents an opportunity to explore these materials for non-structural applications where the design constrain is linked with weight savings.

In terms of the impact performance, WVO once again increased the impact strength of the laminates by up to $135 \%$ and $274 \%$ when compared to formulations manufactured with ENVO and DGEBA, respectively. Due to the reduced brittle nature, these WVO-based composites also presented increased elongation at break versus both neat oil and commercial counterparts. Interestingly, a comparison between GFRC and NFRC in terms of impact strength revealed that laminates produced with untreated flax fibres performed poorer than glass analogues despite previous studies demonstrating the superiority of natural fibres over glass in this property. In this regard, the reduced interaction between the fibre and the matrix observed in the NFRC can result in the formation of micro-cracks at the interface [54]. These act as mechanical stress concentrators, therefore enabling crack propagation and ultimately reducing the impact resistance.

SEM images are used to illustrate the presence of these micro-cracks (Fig. 5). Also, extensive fibre pull-out and debonding of whole fibre bundles (detected even at low magnification levels) are also observed in the NFRC sample. On the other hand, the same resin formulation led to GFRC with well-wetted fibres and fibres breakage rather than fibre pulled-out, indicating that the fibre/matrix interaction is sufficiently higher than the cohesive forces in the fibres.

Given the limited results achieved for composites prepared with untreated FF, chemically-modified fibres were used to boost the mechanical performance of NFRC produced with bio-based matrices. In comparison with laminates produced with WVO and untreated fibres (14 Purif $F F$ ), the alkaline treatment increased the tensile modulus by $36 \%$, Table 4 . Similar improvements are observed when these reinforcements are combined with ENVO-based with matrix, so that the Young's modulus of these laminates exceed the 1.0 GPa mark (59\% higher). SFF fibres are also capable of producing laminates with moduli $35 \%$ and $15 \%$ higher for resins synthesised from neat oil and WVO, respectively. These results demonstrate the improved adhesion deriving from changes in chemical and physical properties of the fibres, with NFF fibres leading to more significant
Table 4 Tensile properties, density and impact strength of composites reinforced with untreated flax (FF), NFF and SFF fibres

\begin{tabular}{lclccc}
\hline Formulation & $\begin{array}{l}\text { Young's modu- } \\
\text { lus (GPa) }\end{array}$ & $\begin{array}{l}\text { Tensile } \\
\text { strength }(\mathrm{MPa})\end{array}$ & $\begin{array}{l}\text { Elongation at } \\
\text { break }(\%)\end{array}$ & Density $\left(\mathrm{g} \mathrm{cm}^{-3}\right)$ & $\begin{array}{l}\text { Impact } \\
\text { strength (kJ } \\
\left.\mathrm{m}^{-2}\right)\end{array}$ \\
\hline 10 Neat FF & $0.48 \pm 0.03$ & $20.3 \pm 0.6$ & $12.2 \pm 1.7$ & $1.08 \pm 0.01$ & $54 \pm 8$ \\
14 Neat FF & $0.65 \pm 0.14$ & $30.2 \pm 1.8$ & $6.3 \pm 0.6$ & $1.08 \pm 0.01$ & $54 \pm 4$ \\
10 Purif FF & $0.47 \pm 0.03$ & $14.2 \pm 1.0$ & $14.3 \pm 2.9$ & $1.03 \pm 0.01$ & $127 \pm 10$ \\
14 Purif FF & $0.60 \pm 0.05$ & $22.7 \pm 0.9$ & $7.0 \pm 1.1$ & $1.11 \pm 0.01$ & $104 \pm 11$ \\
DGEBA FF & $4.6 \pm 0.2$ & $43.2 \pm 3.2$ & $3.6 \pm 0.5$ & $1.17 \pm 0.01$ & $34 \pm 8$ \\
10 Neat NFF & $0.54 \pm 0.04$ & $28.0 \pm 2.9$ & $7.8 \pm 1.3$ & $1.08 \pm 0.01$ & $68 \pm 7$ \\
14 Neat NFF & $1.03 \pm 0.07$ & $34.6 \pm 2.8$ & $6.5 \pm 2.4$ & $1.083 \pm 0.005$ & $60 \pm 10$ \\
10 Purif NFF & $0.47 \pm 0.03$ & $24.6 \pm 3.5$ & $10.9 \pm 2.5$ & $1.088 \pm 0.010$ & $135 \pm 17$ \\
14 Purif NFF & $0.82 \pm 0.15$ & $25.3 \pm 1.7$ & $7.6 \pm 0.8$ & $1.051 \pm 0.010$ & $114 \pm 9$ \\
10 Neat SFF & $0.45 \pm 0.06$ & $20.7 \pm 1.7$ & $7.7 \pm 1.6$ & $1.110 \pm 0.007$ & $59 \pm 4$ \\
14 Neat SFF & $0.88 \pm 0.22$ & $30.7 \pm 2.9$ & $6.4 \pm 0.5$ & $1.080 \pm 0.007$ & $56 \pm 8$ \\
10 Purif SFF & $0.40 \pm 0.10$ & $17.2 \pm 2.4$ & $10.2 \pm 2.5$ & $1.084 \pm 0.009$ & $130 \pm 8$ \\
14 Purif SFF & $0.69 \pm 0.12$ & $21.8 \pm 1.3$ & $7.6 \pm 0.8$ & $1.063 \pm 0.011$ & $109 \pm 10$ \\
\hline
\end{tabular}



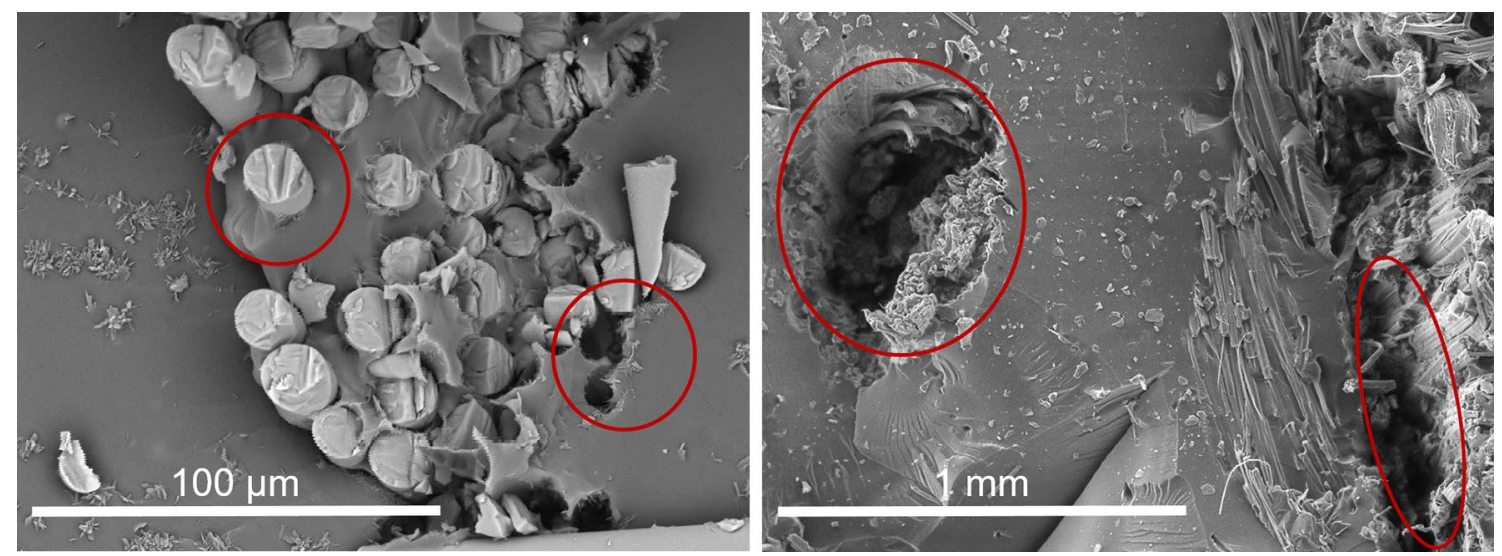

Fig. 5 SEM micrographs of bio-based matrix composites reinforced with glass (left) and flax fibres (right). Red circles highlight observable features (Color figure online)

results. The tensile strength of these panels proved to be also positively affected by the treatment: an increase of $14 \%$ was registered for anhydride-rich panels, while oil-rich formulations, 10 Neat NFF and 10 Purif NFF, presented improvements of 23 and $73 \%$, respectively.

Moreover, chemically-modified fibres also enhanced the impact properties of these laminates. Formulations present improvements between 10 and $23 \%$ in the impact strength in comparison to analogues produced from untreated fibres. Higher impact performance can be associated with the improved compatibility between the fibre and the matrix, therefore reducing the presence of micro-cracks in the interface between the two components. SEM micrographs of composites prepared with modified fibres (Fig. 6) demonstrate the reduction of pull-out and fibre breakage achieved by both treatments, evidencing stronger interfacial interaction between the components. In addition, micrographs obtained at higher magnification $(\times 1000)$ demonstrate that the matrix is efficiently wetting surfaces and grooves created by the chemical modifications step (as highlighted). Consequently, the mechanical load can be more effectively transferred from the matrix to the fibre, enhancing the reinforcing effect.

Radar plots (Fig. 7) summarise the performance of materials produced with untreated flax fibres and those obtained through the best chemical treatment $(\mathrm{NaOH})$. Positive results are observed in all tensile parameters, and the treatment also boosted the impact performance while leaving density and bio-based content virtually unchanged. This collection of improvements are direct consequences of the fibre/matrix interaction enhancement achieved by the treatments. Overall, these findings support the application of the chemical modification to produce NFRC from WVO with better mechanical properties. Nevertheless, it is important to acknowledge the limitations of this approach in comparison with the commercial benchmark. Contrary to what observed for GFRC,
NFRC produced from WVO are indicated for non-structural applications when untreated fibres are used, and intermediate applications after the fibre treatments.

\section{Dynamic Mechanical Properties}

DMA was used to establish relationships between transformations in the microscopic scale such as polymer chain rearrangements, medium scale properties such as fibre/matrix interaction and, finally, at the macroscopic scale through mechanical performance of the material [55]. Curves of storage modulus $\left(E^{\prime}\right)$ versus temperature (Fig. 8) demonstrated that formulations prepared with DGEBA had superior values of $E^{\prime}$ at the elastic plateau in comparison with the bio-based formulations. This characteristic was attributed to superior molecular stiffness of the DGEBA backbone in comparison to the aliphatic backbone of the chemically modified triglycerides.

Also, formulations prepared with resin derived from neat oil demonstrated a higher initial storage modulus than those prepared with WVO as a consequence of its higher degree of functionality [33]. However, other parameters proved to directly affect the dynamic-mechanical properties of the composites and positively affect the properties of laminates produced with WVO-based resin. For example, the comparison of the formulations with different contents of hardener revealed that anhydride-rich networks have increased $\mathrm{E}^{\prime}$ response as consequence of the higher stiffness of these moieties at a molecular level. Therefore, the network became richer in the stiffer component and displayed more elastic behaviour, even though they have been prepared with WVO. The series of composites produced with flax and glass fibres presented very similar values of $\mathrm{E}^{\prime}$; however, DGEBA GF formulation showed $\mathrm{E}^{\prime}$ at an order of magnitude greater than the equivalent produced with flax fibres. 

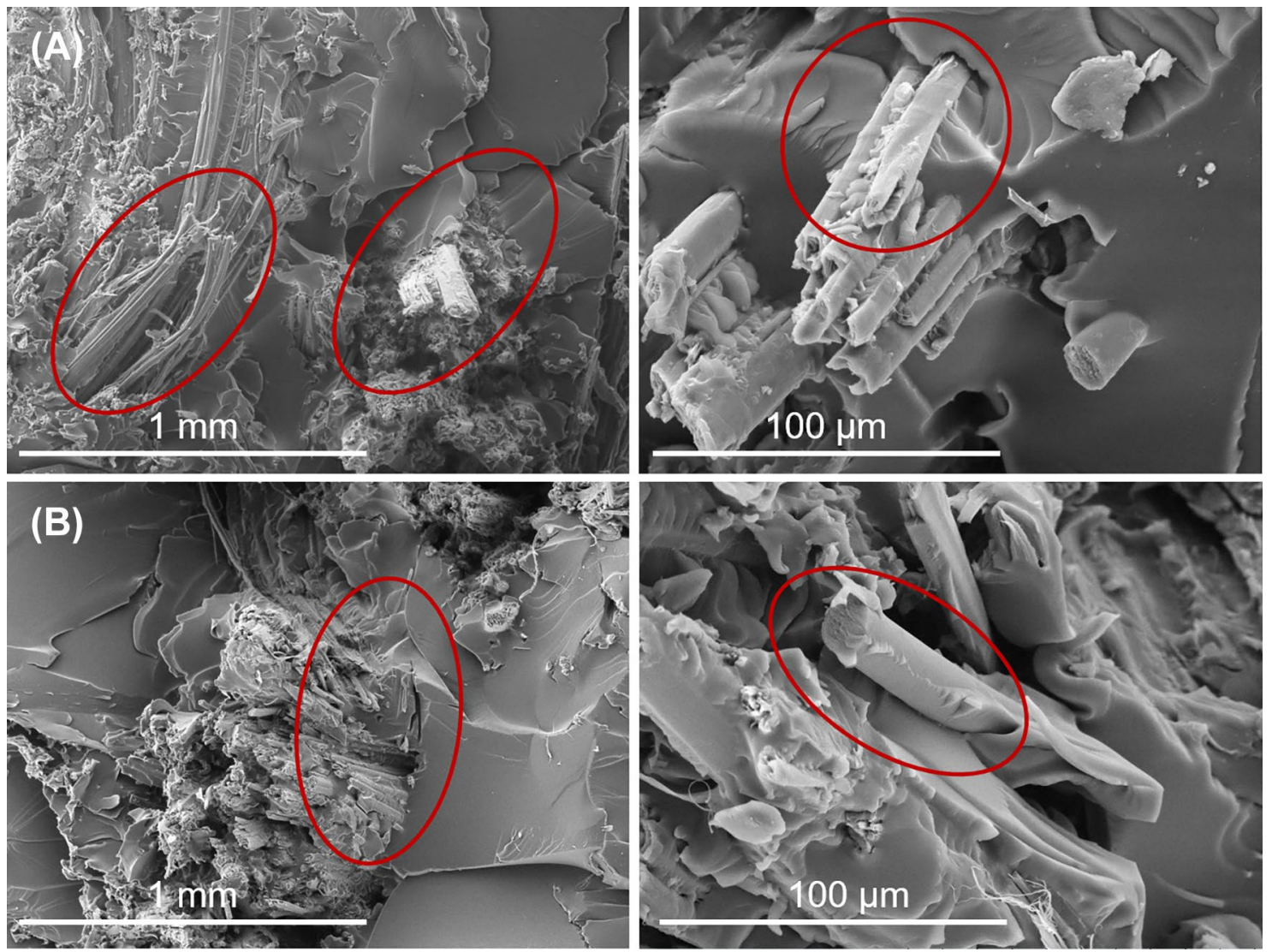

Fig. 6 SEM micrographs of bio-based matri reinforced with flax fibres modified with a $\mathrm{NaOH}$ and $\mathbf{b}$ stearic acid at different magnificaitons ( $\times 100$ on the left and $\times 1000$ on the right). Red circles highlight observable features (Color figure online)

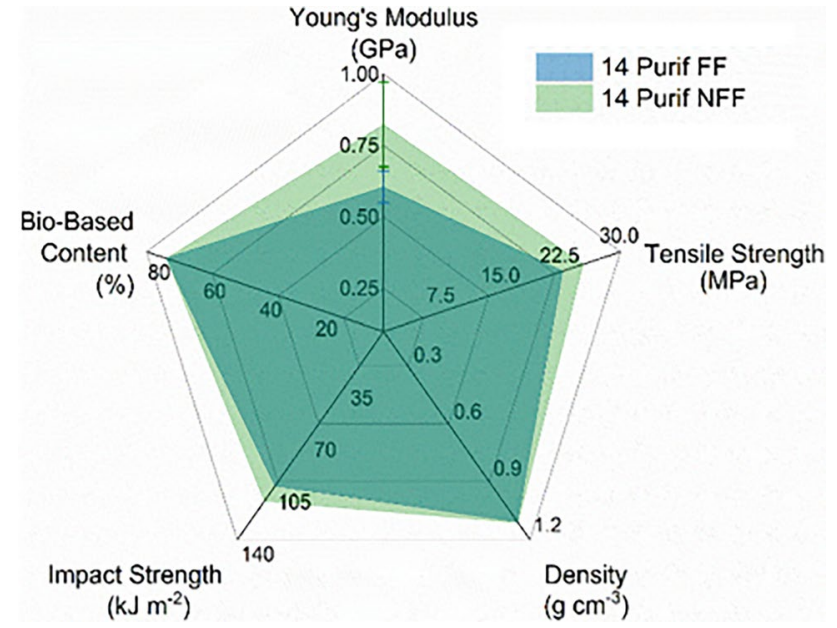

Fig. 7 Radar plot of composites produced with WVO-based resin and reinforced with unmodified (FF) and $\mathrm{NaOH}$-treated flax fibres (NFF) in terms of mechancial properties (tensile and impact), density and bio-based content

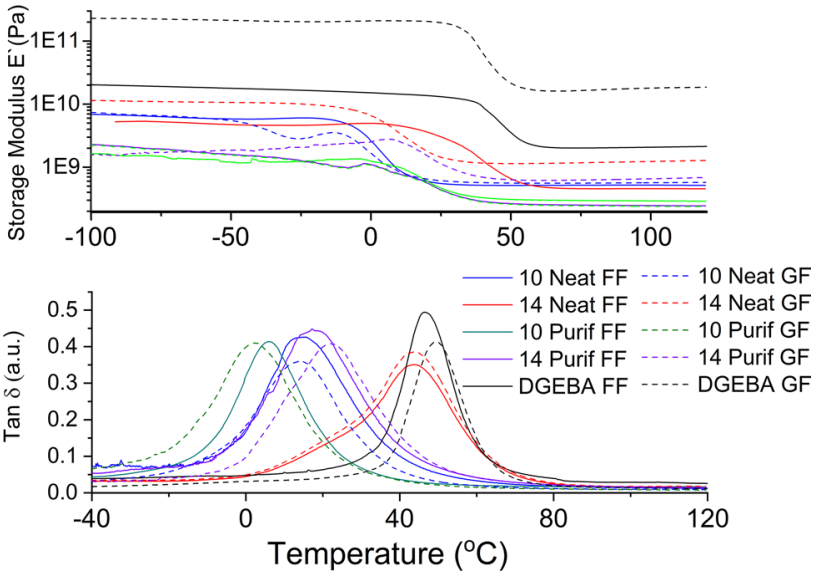

Fig. 8 Storage modulus curves versus temperature of composites produced with flax (above) and glass fibres (below)

$\mathrm{T}_{\mathrm{g}}$ values (Table 5) were obtained through the peaks of the tan $\delta$ curves (Fig. 8), following a similar behaviour to what observed for $E^{\prime}$ values. Composites prepared with anhydride-rich polymer matrices and more functional resins presented superior $\mathrm{T}_{\mathrm{g}}$ due to a combination of more 
Table $5 \mathrm{~T}_{\mathrm{g}}$ values for GFRC and NFRC formulations

\begin{tabular}{lrll}
\hline Formulation & $\mathrm{T}_{\mathrm{g}}\left({ }^{\circ} \mathrm{C}\right)$ & Formulation & $\mathrm{T}_{\mathrm{g}}\left({ }^{\circ} \mathrm{C}\right)$ \\
\hline 10 Neat FF & 14.6 & 10 Neat NFF & 34.8 \\
14 Neat FF & 43.9 & 14 Neat NFF & 44.1 \\
10 Purif FF & 6.6 & 10 Purif NFF & 24.4 \\
14 Purif FF & 17.9 & 14 Purif NFF & 34.5 \\
DGEBA FF & 46.7 & & \\
10 Neat GF & 13.3 & 10 Neat SFF & 28.8 \\
14 Neat GF & 43.6 & 14 Neat SFF & 30.2 \\
10 Purif GF & 3.4 & 10 Purif SFF & 10.9 \\
14 Purif GF & 22.2 & 14 Purif SFF & 29.6 \\
DGEBA GF & 49.5 & & \\
\hline
\end{tabular}

rigid and denser networks. The presence of one single tan $\delta$ peak in the curves indicates the formation of a single polymeric phase, but their broad nature evidences the formation of heterogeneous networks from the crosslink distribution point of view [56]. In the context of the utilisation vegetable oil-based resins, this characteristic derives from the statistical distribution of double bonds along the mixed triglycerides found in these natural materials, which are composed by mixed fatty acids [57]. Additionally, no residual cure or secondary transitions (i.e., $\mathrm{T}_{\beta}$ ) were detected in this temperature range.

Effects of the modification strategy were also investigated from the dynamic-mechanical properties. Composite followed similar behaviours to those previously observed for materials produced with unmodified fibres regarding $\mathrm{E}^{\prime}$ (Fig. 9). On the other hand, values of $\mathrm{T}_{\mathrm{g}}$ observed for composites prepared with NFF and SFF were superior to those obtained from untreated flax fibres. This change illustrates the improvements in the fibre matrix interactions: with better interfacial interaction, reinforcing fibres are able to introduce an immobilization effect in the polymeric matrix. Therefore, chain mobility is reduce, which is physically translated into higher $\mathrm{T}_{\mathrm{g}}$ values [58].

From the group of materials produced with modified fibres explored in this study, NFF-reinforced composites demonstrated the best improvements in $\mathrm{T}_{\mathrm{g}}$. This indicated mercerization promoted the best enhancement of the interfacial interaction between the two methods herein investigated. Also, the additional interaction introduced by the chemical treatments enabled bio-based networks to present $\mathrm{T}_{\mathrm{g}}$ above room temperature, feature which was reflected in the tensile performance of these laminates. This is an interesting finding since $T_{g}$ is often used as a design parameter. Overall, the fibre modification was responsible for producing laminates with more competitive mechanical and physical performance over those obtained with untreated flax. Also, it is important to highlight that the DGEBA formulation used as benchmark $\left(\right.$ SuperSap ${ }^{\circledR}$ ) present reduced $\mathrm{T}_{\mathrm{g}}$ versus

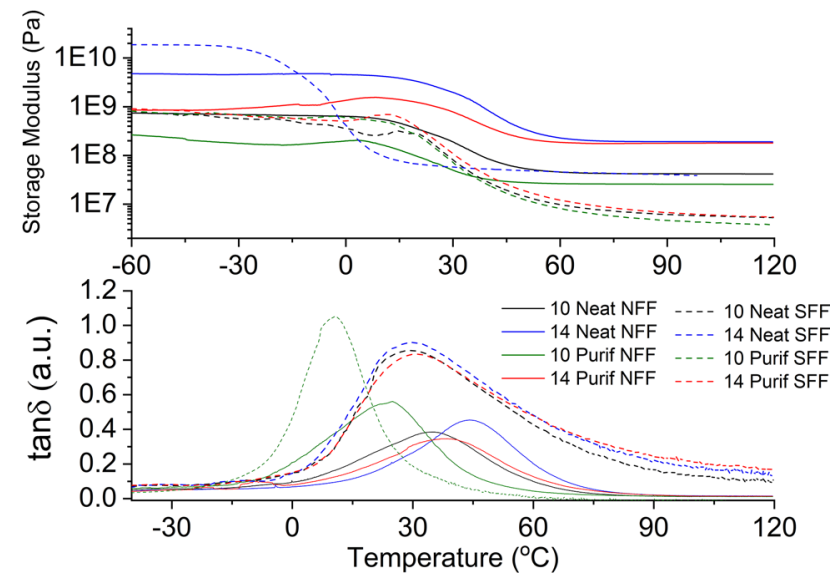

Fig. 9 Storage modulus (above) and tan (below) curves versus temperature of composites produced with NFF and SFF

other high-performance DGEBA systems (e.g. EPIKOTETM) because it presents bio-based additives in the formulation.

\section{Thermal Properties}

Thermogravimetric curves of the GFRC and NFRC, as well as their respective first derivative curves of weight loss with respect to temperature are presented in Fig. 10a-d. The presence of non-volatile residues at the end of the analysis of NFRC (modified/unmodified fibres) is associated with aromatic compounds in the lignin structure, which form highly condensed products and lead to the formation of carbonized residues [59]. On the other hand, residues observed in the weight loss curves of GFRC reveal the presence of undegraded reinforcing agents as consequence of the superior thermal stability of glass fibres. The reduction of the quantity of non-volatile residues observed for materials produced with SFF directly demonstrates the delignification caused by the treatment based on stearic acid is the most effective one between the treatments.

Values of $\mathrm{T}_{\text {Onset }}$ of GFRC (Table 6) revealed a correlation between thermal stability and anhydride content. As observed previously, this behaviour can be related to the reduced thermal stability of this moiety in comparison with the triglyceride-derived units [40]. In contrast, $\mathrm{T}_{\text {Onset }}$ values for NFRC fluctuated with no particular order. In fact, the polymeric network and the flax fibres undergo thermal degradation processes at very similar temperature ranges. Therefore, the observable weight loss behaviour represented the combination of simultaneous degradation phenomena, consequently masking the effect caused by the reduced stability of the anhydride.

Composites prepared with alkaline-treated fibres present a slight reduction in $\mathrm{T}_{\text {Onset }}$, reflecting the results observed for the thermogravimetric analysis of the fibres. Nevertheless, 
(A)
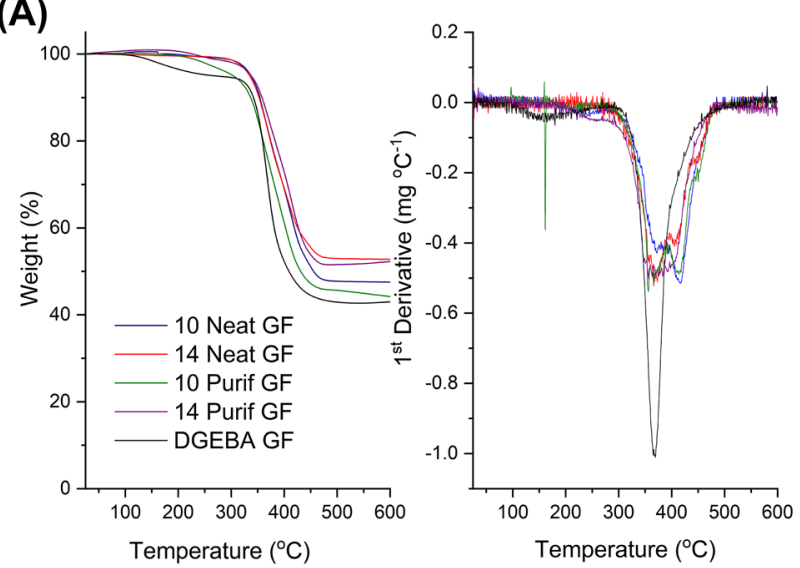

(C)
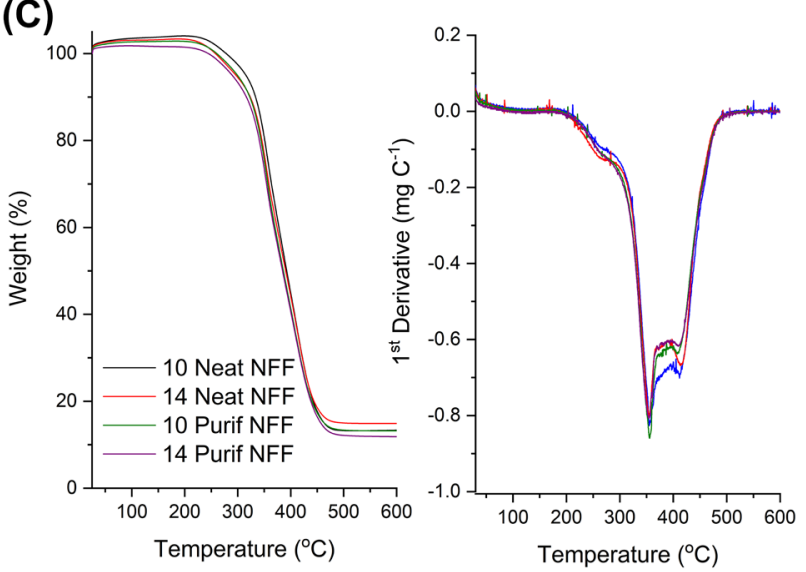
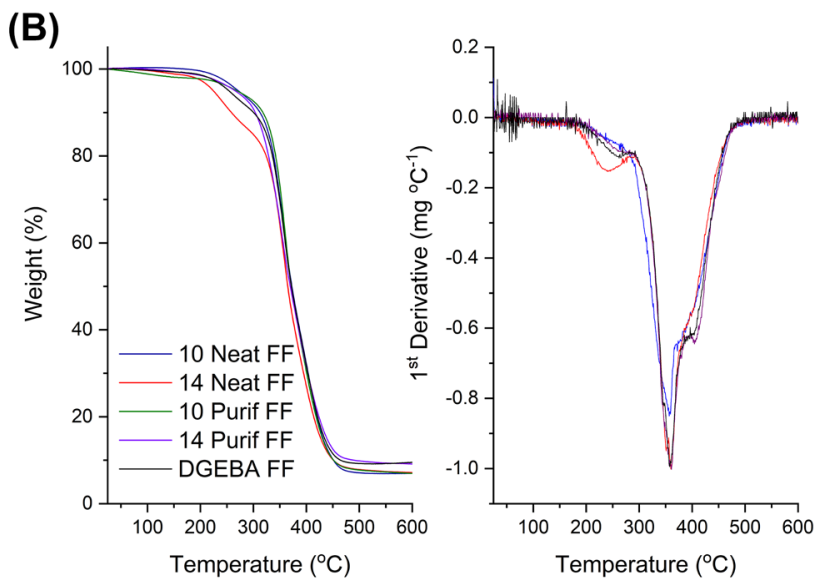

(D)

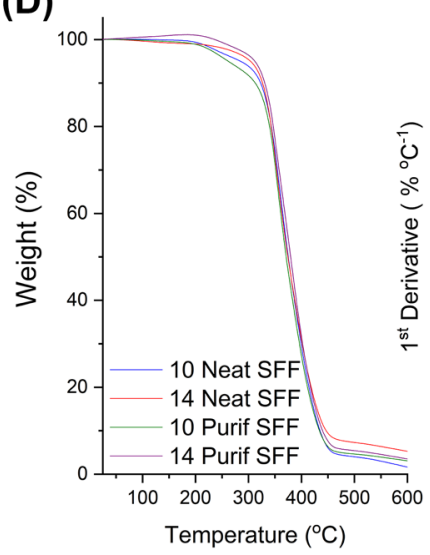

Fig. 10 Thermograms and first mass loss derivative with respect to temperature composites reinforced with a glass fibres, $\mathbf{b}$ flax fibres, $\mathbf{c}$ alkalitreated fibres and $\mathbf{d}$ stearic acid-treated fibres, from 25 to $600{ }^{\circ} \mathrm{C}$, under $\mathrm{N}_{2}$ atmosphere

the reduction in thermal stability is not as accentuated as in the comparison between FF and NFF. This finding evidenced that the polymer matrix is capable of retarding the degradation effect thanks to its higher thermal stability and because of a synergistic effect, which makes the $\mathrm{T}_{\text {Onset }}$ of the composites higher than that observed for the isolated materials.

Thermal degradation could be followed in more details through the curves of first derivative. Since glass fibres do not present any thermal degradation event in this temperature range, curves obtained from GFRC (Fig. 10a) could be used to understand phenomena exclusive associated with degradation of the polymeric matrix. Derivatives revealed that thermal degradation of the network took place as a broad event from 340 to $420{ }^{\circ} \mathrm{C}$. On the other hand, composites prepared with plant fibres (Fig. 10b-d) presented a maximum in approximately $350{ }^{\circ} \mathrm{C}$ that was assigned with the degradation of the cellulosic units of the fibre and confirmed by the values of $\mathrm{T}_{\mathrm{Max}}$. The second degradation event evidenced by the peak at $400{ }^{\circ} \mathrm{C}$ was therefore associated with the simultaneous thermal degradation of the cross-linked units. In addition, particularly in SFF this peak is not clearly observed because of the degradation of the stearic acid as well. Also, the thermal event exclusively found in the $14 N e a t F F$ at $235^{\circ} \mathrm{C}$ is associated with thermodegradation of unreacted hardener. Most importantly, TGA results revealed that the use of resins produced with WVO causes no sacrifices from a thermal stability standpoint in comparison with analogues produced from neat oil or the commercial epoxy.

\section{Conclusions}

Composite laminates were prepared by wet lay-up with bio-based epoxy resin produced from WVO reinforced with glass, flax and chemically modified flax fibres, creating a library of new composites based on the waste valorisation concept. The comparison between the mechanical properties of these materials revealed a strong dependence on the reinforcing fibre selected. Bio-based GRFC emulated the tensile properties of the commercial benchmark and laminates produced with virgin oil in terms of Young`s 
Table 6 Temperature of initial degradation $\left(\mathrm{T}_{\text {Onset }}\right)$ and temperature of maximum degradation rate $\left(\mathrm{T}_{\mathrm{Max}}\right)$ of GFRC and NFRC formulations

\begin{tabular}{lll}
\hline Formulation & $\mathrm{T}_{\text {Onset }}\left({ }^{\circ} \mathrm{C}\right)$ & $\mathrm{T}_{\text {Max }}\left({ }^{\circ} \mathrm{C}\right)$ \\
\hline 10 Neat GF & 337.6 & 414.9 \\
14 Neat GF & 330.6 & 416.3 \\
10 Purif GF & 336.8 & 413.7 \\
14 Purif GF & 330.8 & 407.3 \\
DGEBA GF & 348.5 & 369.0 \\
10 Neat FF & 339.3 & 359.0 \\
14 Neat FF & 336.8 & 360.3 \\
10 Purif FF & 331.1 & 361.0 \\
14 Purif FF & 333.7 & 360.3 \\
DGEBA FF & 347.0 & 370.3 \\
10 Neat NFF & 324.0 & 355.0 \\
14 Neat NFF & 326.2 & 354.1 \\
10 Purif NFF & 322.1 & 355.3 \\
14 Purif NFF & 320.0 & 353.3 \\
10 Neat SFF & 331.3 & 368.3 \\
14 Neat SFF & 323.0 & 353.7 \\
10 Purif SFF & 326.1 & 352.3 \\
14 Purif SFF & 325.4 & 351.0 \\
\hline
\end{tabular}

modulus. On the other hand, untreated flax fibre reinforced composites presented different tensile properties due to incompatibility between the polymeric matrix and the fibres, being suitable for non-structural applications only. Chemical modifications with $\mathrm{NaOH}$ and stearic acid increased tensile and impact properties without sacrificing other parameters such as density. Improvements in the fibre/matrix interaction were confirmed by SEM images and DMA, which revealed an increased in $\mathrm{T}_{\mathrm{g}}$ (values above room temperature). Adjustments in the formulation through the selection of a suitable hardener molar ratio mitigated the losses caused using resins with reduced functionality in terms of mechanical and dynamic-mechanical properties. Most importantly, the use of waste-based resins greatly improved impact properties in comparison with the brittle DGEBA matrix in all cases and led to reductions in density, demonstrating the usability of WVO-based formulations in applications that demand toughness, stiffness and light-weight over strength. The use of WVO to replace virgin oil or DGEBA caused no observable effect on thermal stability, which proved to be mainly ruled by the natural fibre. In conclusion, epoxy resins from waste vegetable oil appear as more sustainable alternative for composites laminates for both structural (with glass) and non-structural applications (with modified flax), opening space for the development of a next generation of biobased materials based on the waste valorisation principle.
Acknowledgements The authors would like to thank the National Council for Scientific and Technological Development (CNPq), Brazil [203118/2014-6] for their support of this work.

Open Access This article is distributed under the terms of the Creative Commons Attribution 4.0 International License (http://creativeco mmons.org/licenses/by/4.0/), which permits unrestricted use, distribution, and reproduction in any medium, provided you give appropriate credit to the original author(s) and the source, provide a link to the Creative Commons license, and indicate if changes were made.

\section{References}

1. Faruk O, Bledzki AK, Fink H-P, Sain M (2012) Biocomposites reinforced with natural fibers: 2000-2010. Prog Polym Sci 37:15521596. https://doi.org/10.1016/j.progpolymsci.2012.04.003

2. Wood B, Coles SR, Maggs S et al (2011) Use of lignin as a compatibiliser in hemp/epoxy composites. Compos Sci Technol 71:1804-1810

3. Bledzki AK, Gassan J (1999) Composites reinforced with cellulose based fibres. Prog Polym Sci 24:221-274

4. Mohanty AK, Misra M, Hinrichsen G (2000) Biofibres, biodegradable polymers and biocomposites: an overview. Macromol Mater Eng 276-277:1-24

5. Ramesh M, Palanikumar K, Reddy KH (2017) Plant fibre based bio-composites: sustainable and renewable green materials. Renew Sustain Energy Rev 79:558-584. https://doi.org/10.1016/j. rser.2017.05.094

6. Dicker MPM, Duckworth PF, Baker AB et al (2014) Green composites: a review of material attributes and complementary applications. Composite Part A 56:280-289. https://doi.org/10.1016/j. compositesa.2013.10.014

7. Meredith JO, Ebsworth R, Coles SR et al (2012) Natural fibre composite energy absorption structures. Compos Sci Technol 72:211-217

8. Meredith J, Coles SR, Powe R et al (2013) On the static and dynamic properties of flax and Cordenka epoxy composites. Compos Sci Technol 80:31-38. https://doi.org/10.1016/j.comps citech.2013.03.003

9. Samper MD, Petrucci R, Sánchez-Nacher L et al (2015) New environmentally friendly composite laminates with epoxidized linseed oil (ELO) and slate fiber fabrics. Composite Part B 71:203-209. https://doi.org/10.1016/j.compositesb.2014.11.034

10. Mantzaridis C, Brocas A-L, Llevot A et al (2013) Rosin acid oligomers as precursors of DGEBA-free epoxy resins. Green Chem 15:3091. https://doi.org/10.1039/c3gc41004h

11. Ng F, Couture G, Philippe C et al (2017) Bio-based aromatic epoxy monomers for thermoset materials. Molecules 22:149. https ://doi.org/10.3390/molecules22010149

12. Chen MY, Ike M, Fujita M (2002) Acute toxicity, mutagenicity, and estrogenicity of bisphenol-A and other bisphenols. Environ Toxicol 17:80-86. https://doi.org/10.1002/tox.10035

13. Moore-Ambriz TR, Acuña-Hernández DG, Ramos-Robles B et al (2015) Exposure to bisphenol A in young adult mice does not alter ovulation but does alter the fertilization ability of oocytes. Toxicol Appl Pharmacol 289:507-514. https://doi.org/10.1016/j. taap.2015.10.010

14. Okada H, Tokunaga T, Liu X et al (2008) Direct evidence revealing structural elements essential for the high binding ability of bisphenol a to human estrogen-related receptor-gamma. Environ Health Perspect 116:32-38. https://doi.org/10.1289/ehp.10587

15. The European Comission Comission Regulation (EU) No 10/2011 of 14 January 2011 on plastic materials and articles intended to come into contact with food. Off J Eur Union 2011 
16. Tan SG, Chow WS (2010) Biobased epoxidized vegetable oils and its greener epoxy blends: a review. Polym Plast Technol Eng 49:1581-1590. https://doi.org/10.1080/03602559.2010.512338

17. Maiorana A, Ren L, Lo Re G et al (2015) Bio-based epoxy resin toughening with cashew nut shell liquid-derived resin. Green Mater 3:80-92. https://doi.org/10.1680/jgrma.15.00019

18. Seniha Güner F, Yağcı Y, Tuncer Erciyes A (2006) Polymers from triglyceride oils. Prog Polym Sci 31:633-670. https://doi. org/10.1016/j.progpolymsci.2006.07.001

19. Auvergne R, Caillol S, David G, et al (2014) Biobased thermosetting epoxy: present and future. Chem Rev 114:1082-1115. https ://doi.org/10.1021/cr3001274

20. Biermann U, Bornscheuer U, Meier M, et al (2011) Oils and fats as renewable raw materials in chemistry. Angew Chem Int Ed Engl 50:3854-3871. https://doi.org/10.1002/anie.201002767

21. Xia Y, Larock RC (2010) Vegetable oil-based polymeric materials: synthesis, properties, and applications. Green Chem 12:1893. https://doi.org/10.1039/c0gc00264j

22. Zhang Y, Li Y, Thakur VK et al (2018) High-performance thermosets with tailored properties derived from methacrylated eugenol and epoxy-based vinyl ester. Polym Int 67:544-549. https://doi. org/10.1002/pi.5542

23. Zhang Y, Li Y, Thakur VK et al (2018) Bio-based reactive diluents as sustainable replacements for styrene in MAESO resin. RSC Adv 8:13780-13788. https://doi.org/10.1039/C8RA00339D

24. Zhang Y, Thakur VK, Li Y et al (2018) Soybean-oil-based thermosetting resins with methacrylated vanillyl alcohol as bio-based, low-viscosity comonomer. Macromol Mater Eng 303:1700278. https://doi.org/10.1002/mame.201700278

25. Boquillon $\mathrm{N}$ (2006) Use of an epoxidized oil-based resin as matrix in vegetable fibers-reinforced composites. J Appl Polym Sci 101:4037-4043. https://doi.org/10.1002/app.23133

26. Liu W, Chen T, Xie T, Qiu R (2016) Soybean oil-based thermosets with N-vinyl-2-pyrrolidone as crosslinking agent for hemp fiber composites. Composite Part A 82:1-7. https://doi.org/10.1016/j. compositesa.2015.11.035

27. Wool RP (2005) Composites and foams from plant oil-based resins. In: Wool RP, Sun XS (eds) Bio-based polymers and composites. Elsevier Inc., Amsterdam, pp 114-148

28. Liu Z, Erhan SZ, Akin DE, Barton FE (2006) “ Green ” composites from renewable resources : preparation of epoxidized soybean oil and flax fiber composites. J Agric Food Chem 54:2134-2137

29. Pfister DP, Larock RC (2013) Green composites using switchgrass as a reinforcement for a conjugated linseed oil-based resin. J Appl Polym Sci 127:1921-1928. https://doi.org/10.1002/app.37536

30. Adekunle K, Ãkesson D, Skrifvars M (2010) Biobased composites prepared by compression molding with a novel thermoset resin from soybean oil and a natural-fiber reinforcement. J Appl Polym Sci. https://doi.org/10.1002/app.31634

31. Zhang MQ, Rong MZ, Lu X (2005) Fully biodegradable natural fiber composites from renewable resources: all-plant fiber composites. Compos Sci Technol 65:2514-2525. https://doi. org/10.1016/j.compscitech.2005.06.018

32. Thakur VK, Thakur MK, Raghavan P, Kessler MR (2014) Progress in green polymer composites from lignin for multifunctional applications: a review. ACS Sustain Chem Eng 2:1072-1092. https://doi.org/10.1021/sc500087z

33. Fernandes FC, Lehane D, Kirwan K, Coles SR (2017) Epoxy resin blends and composites from waste vegetable oil. Eur Polym J 89:449-460. https://doi.org/10.1016/j.eurpolymj.2017.02.005

34. Anastas P, Warner JC (1998) Green chemistry: theory and practice. Oxford University Press, New York

35. Anastas P, Zimmerman JB (2003) Sustainability requires objectives at the molecular, product, process, and system levels. Environ Sci Technol 37:94A-101A. https://doi.org/10.1021/es032373g
36. Choe E, Min DB (2007) Chemistry of deep-fat frying oils. J Food Sci 72:R77-86. https://doi.org/10.1111/j.1750-3841.2007.00352 .x

37. Gunstone FD (2013) Non-food use of vegetable oils. Lipid Technol 25:72-72. https://doi.org/10.1002/lite.201300258

38. Huang K, Liu Z, Zhang J et al (2014) Epoxy monomers derived from tung oil fatty acids and its regulable thermosets cured in two synergistic ways. Biomacromolecules 15:837-843. https:// doi.org/10.1021/bm4018929

39. Piccinno F, Hischier R, Seeger S, Som C (2015) Life cycle assessment of a new technology to extract, functionalize and orient cellulose nanofibers from food waste. ACS Sustain Chem Eng 3:1047-1055. https://doi.org/10.1021/acssuschemeng.5b00209

40. Fernandes FC, Kirwan K, Wilson PR, Coles SR, (2018) Optimisation of waste vegetable oil-based thermoset polymers. Green Mater 6:38-46

41. Jacob M, Thomas S, Varughese KT (2004) Mechanical properties of sisal/oil palm hybrid fiber reinforced natural rubber composites. Compos Sci Technol 64:955-965. https://doi.org/10.1016/S0266 $-3538(03) 00261-6$

42. Kalaprasad G, Francis B, Thomas S et al (2004) Effect of fibre length and chemical modifications on the tensile properties of intimately mixed short sisal / glass hybrid fibre reinforced low density polyethylene composites. Polym Int 1638:1624-1638. https://doi. org/10.1002/pi.1453

43. Choe E, Min DB (2005) Chemistry and reactions of reactive oxygen species in foods. J Food Sci 70:142-159

44. George J, Sreekala MS, Thomas S (2001) A review on interface modification and characterization of natural fiber reinforced plastic composites. Polym Eng Sci 41:1471-1485. https://doi. org/10.1002/pen.10846

45. Kabir MM, Wang H, Lau KT, Cardona F (2012) Chemical treatments on plant-based natural fibre reinforced polymer composites: an overview. Composite Part B 43:2883-2892

46. Rong MZ, Zhang MQ, Liu Y et al (2001) The effect of fiber treatment on the mechanical properties of unidirectional sisal-reinforced epoxy composites. Compos Sci Technol 61:1437-1447

47. Barreto ACH, Rosa DS, Fechine PBA, Mazzetto SE (2011) Properties of sisal fibers treated by alkali solution and their application into cardanol-based biocomposites. Composite Part A 42:492500. https://doi.org/10.1016/j.compositesa.2011.01.008

48. Wang B, Panigrahi S, Tabil L, Crerar W (2007) Pre-treatment of flax fibers for use in rotationally molded biocomposites. J Reinf Plast Compos 26:447-463. https://doi.org/10.1177/0731684406 072526

49. Martin AR, Martins MA, da Silva ORRF, Mattoso LHC (2010) Studies on the thermal properties of sisal fiber and its constituents. Thermochim Acta 506:14-19. https://doi.org/10.1016/j. tca.2010.04.008

50. Oushabi A, Sair S, Hassani FO et al (2017) The effect of alkali treatment on mechanical, morphological and thermal properties of date palm fibers (DPFs ): study of the interface of DPF-polyurethane composite. S Afr J Chem Eng 23:116-123. https://doi. org/10.1016/j.sajce.2017.04.005

51. Li X, Tabil LG, Panigrahi S (2007) Chemical treatments of natural fiber for use in natural fiber-reinforced composites: a review. J Polym Environ 15:25-33. https://doi.org/10.1007/s1092 4-006-0042-3

52. Miyagawa H, Misra M, Drzal LT, Mohanty AK (2005) Fracture toughness and impact strength of anhydride-cured biobased epoxy. Polym Eng Sci 45:487-495. https://doi.org/10.1002/pen.20290

53. Mashouf Roudsari G, Mohanty AK, Misra M (2017) Green approaches to engineer tough biobased epoxies: a review. ACS Sustain Chem Eng 5:9528-9541. https://doi.org/10.1021/acssu schemeng.7b01422 
54. Yang HS, Kim HJ, Park HJ et al (2007) Effect of compatibilizing agents on rice-husk flour reinforced polypropylene composites. Compos Struct 77:45-55. https://doi.org/10.1016/j.compstruct 2005.06.005

55. Costa CSMF, Fonseca AC, Serra AC et al (2016) Dynamic mechanical thermal analysis of polymer composites reinforced with natural fibers. Polym Rev 56:362-383. https://doi. org/10.1080/15583724.2015.1108334

56. Campanella A, La Scala JJ, Wool RP (2009) The use of acrylated fatty acid methyl esters as styrene replacements in triglyceridebased thermosetting polymers. Polym Eng Sci 49:2384-2392. https://doi.org/10.1002/pen

57. Karak N (2012) Vegetable oil-based polymers. Woodhead Publishing, Cambridge

58. De Paiva JMF, Frollini E (2006) Unmodified and modified surface sisal fibers as reinforcement of phenolic and lignophenolic matrices composites: thermal analyses of fibers and composites. Macromol Mater Eng 291:405-417. https://doi.org/10.1002/ mame.200500334

59. Watkins D, Nuruddin M, Hosur M et al (2015) Extraction and characterization of lignin from different biomass resources. J Mater Res Technol 4:26-32. https://doi.org/10.1016/j. jmrt.2014.10.009

Publisher's Note Springer Nature remains neutral with regard to jurisdictional claims in published maps and institutional affiliations. 